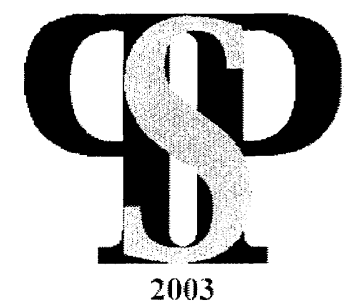

\title{
A 1983-1993-2003 STATE-OF-THE-ART REPORT ON SEISMIC ANALYSIS
}

\author{
T.E. Kelly ${ }^{1}$
}

\begin{abstract}
A 2003 state-of-the-art report on seismic analysis for structural engineers would be similar to one that could have been produced in 1993 or 1983, and in fact not much different from 1973. Development of structural engineering analysis tools has not kept pace with the rapid improvement in computer hardware.

Our common analysis tools ignore either nonlinearity (response spectrum analysis), dynamic effects (pushover analysis), or both (equivalent static analysis) even though these effects are critical in evaluating the performance of a structure under earthquake loads.

This paper examines the effects of nonlinearity and dynamic loads on the response of structures and illustrates cases where ignoring either of these leads to erroneous results. Given this need for nonlinear dynamic analysis, impediments to more widespread use are discussed and areas where more research information is required are identified.

The conclusion of this paper is that our profession needs to be more active in implementing software development, graduate training in analysis and the processing of research results to a format suited for analysis models. We have a wealth of research information providing detailed response of structural components but, by failing to convert this into detailed rules for nonlinear analysis, we are neglecting much of the value in this research.
\end{abstract}

\section{BIOGRAPHICAL NOTE}

Trevor Kelly completed a BE at the University of Canterbury in 1973 and an ME, under the supervision of Professor Paulay, in 1974. His research report, related to the nonlinear analysis of concrete structures, initiated an interest in this field which has continued throughout his career. He initially worked as a structural designer in New Zealand and California and, over the last 20 years, has specialised in structural engineering fields which utilise nonlinear analysis, such as base isolation, energy dissipation and performance based evaluation of existing buildings. In his current position, Mr Kelly directs the technical developments at Holmes Consulting Groups, particularly as they relate to structural analysis and computer software development.

\footnotetext{
'Holmes Consulting Group, Auckland, New Zealand
} 


\section{INTRODUCTION}

The response of structures to earthquake motions is governed by the laws of mechanics and physics, laws which were formulated by Sir Isaac Newton and his contemporaries, Robert Hooke and Joseph Raphson, in the 1600's.

From the 1960's computers provided a means of solving these equations and the development of nonlinear analysis software proceeded rapidly. By the 1970's nonlinear analysis was possible but tediously slow, requiring several hours on a mainframe computer for a single earthquake analysis of a simple plane frame. The results of the analyses provided valuable information on the ductility demand on yielding members, and maximum forces on members intended to remain elastic, but the procedure was not practical for design offices.

Thirty years later, computer hardware has improved execution speed by over three orders of magnitude and the cost of that hardware has reduced by a similar proportion. Modern computer hardware can efficiently solve the laws of motion, as can be seen by games on Playstation ${ }^{\circledR}$ or $\mathrm{XBox}^{\odot}$. The plane frame analysis which took hours on a mainframe can now be completed in seconds on a desktop computer. With this computing power on each engineer's desk, it would be expected that nonlinear analysis would be common in structural design offices. It is not.

The structural engineering profession is moving toward Performance Based Design, for both existing and new buildings. An evaluation of performance under seismic load conditions requires that we quantify the response. This can only be done by including both dynamic and nonlinear effects. These effects include force distributions which adapt to yielding behaviour, the number of simultaneously yielding beams, biaxial load effects and other aspects of response which are unique to each structure.

In this paper, the current state of our analysis tools is examined. Some examples of the dynamic response of yielding structures illustrate why more sophisticated analysis can provide more reliable indications of seismic performance. The impediments to more widespread use to this type of analysis are then discussed.

\section{MILESTONES IN STRUCTURAL ANALYSIS}

Earthquakes are a dynamic phenomenon. Fault movements cause waves which impart accelerations into structures on the surface of the earth. The response of the structure is governed by the laws of physics. For a structure subjected to ground accelerations, $\ddot{u}_{g}$, the response is a function of the system mass, $\mathrm{M}$, stiffness, $\mathrm{K}$ and damping, $\mathrm{C}$, as determined from the equation of motion:

$$
\mathrm{Mu}+\mathrm{C} \dot{\mathrm{u}}+\mathrm{Ku}=-\mathrm{Mu}_{\mathrm{g}}
$$

The laws governing dynamic response were formulated hundreds of years ago. Robert Hooke postulated that stress was proportional to strain in 1676, supplying the stiffness term, K. His great rival, Sir Isaac Newton, formulated his laws of motion 20 years later in 1687 , providing the mass term, M. In collaboration with Joseph Raphson, the NewtonRaphson method for solving this type of equation followed shortly after, in 1690.

The missing element was $\mathrm{C}$, the damping, which followed later when Lord Rayleigh published details of his "dissipation function" in 1877 (Rayleigh, 1877), a function now commonly known as Rayleigh damping. By 1877 the theoretical basis for nonlinear structural analysis was in place. There was no practical method of implementing these formulations until the development of the finite element method, first described by Courant (Courant, 1943) and fully developed by a definitive paper by Turner, Clough, Martin \& Topp (Turner et al, 1956). The terminology, finite element method, appears to have been first coined by Professor Clough in 1960.

\section{CURRENT STATUS OF STRUCTURAL ANALYSIS}

The first programs for structural analysis using the direct stiffness method were developed in the 1960's and by the early 1970's finite element and frame analysis programs were replacing manual analysis methods, such as moment distribution, and approximate methods, such as Muto analysis.

Table 1. Analysis Software

\begin{tabular}{lll}
\hline Program & Capability & $\begin{array}{l}\text { Year } \\
\text { Authored }\end{array}$ \\
\hline SAP & Linear elastic 3D & 1973 \\
RUAUMOKO & Nonlinear 2D & 1973 \\
DRAIN-2D & Nonlinear 2D & 1973 \\
ETABS & Linear elastic 3D & 1975 \\
ANSR & Nonlinear 3D & 1975 ANSR-I \\
& & 1979 ANSR-II \\
& & 1982 ANSR-III \\
\hline
\end{tabular}

In the 1970's the University of California in Berkeley was the origin of many of the computer programs which are still in use today. Concurrently, the program now called Ruaumoko was under development at the University of Canterbury. Following this decade of frenetic development, a full set of software tools was available for seismic analysis twenty years ago, in 1983 (Table 1).

These programs were developed for mainframe computers. Their use was generally restricted to schools of engineering, with limited access by some design firms through computer bureaux. The complexity and expense of running these programs limited their application. However, in the 1980's desktop computers provided increasing processing power in design offices and reduced the cost drastically. Since then, there has been a continual process of increasing computer capability at decreasing cost.

Figure 1 shows a building our company uses to benchmark hardware, the Cooper Lybrand Tower in Auckland. This is a 37 story perimeter frame building with 1600 yielding elements. When the building was designed in 1985, each non-linear analysis took 30 hours on a $\$ 250,000$ super minicomputer. Now, a single analysis can be performed in less than 1 minute on a $\$ 3,000$ desktop computer. 

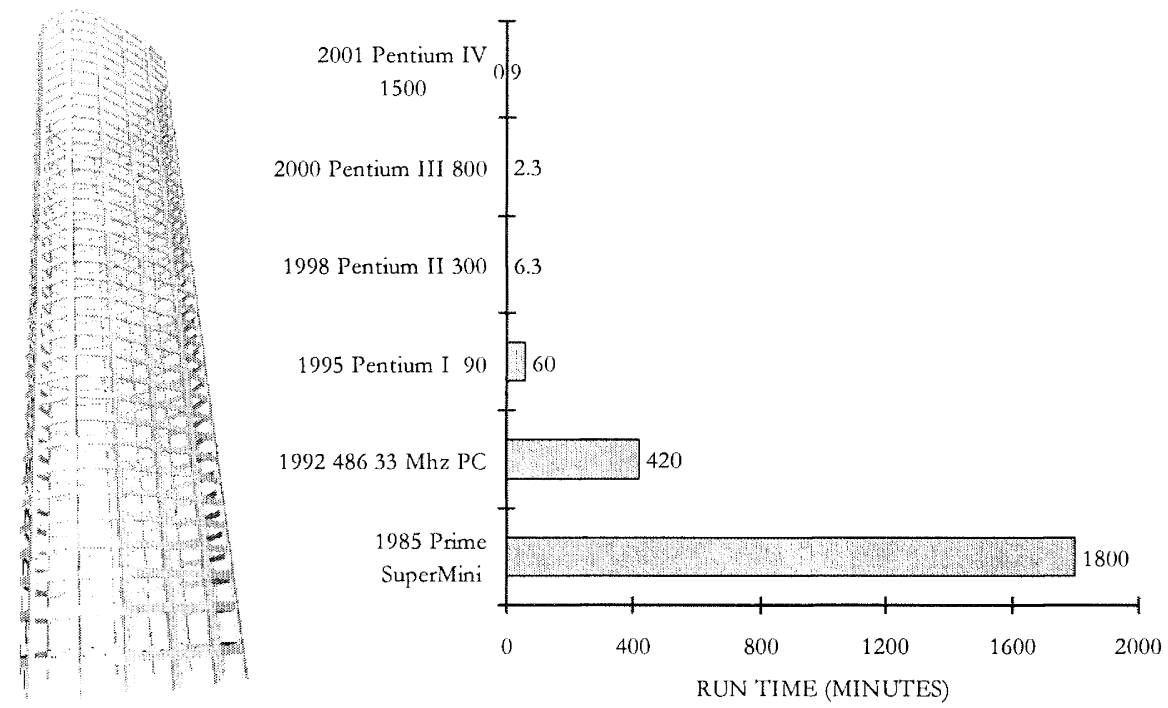

Figure 1. Execution Time for Prototype Structure

In spite of this capability, our main analysis tools in 2003 are still linear elastic programs, such as SAP2000, ETABS (Habibullah, 2001) or other programs with similar capabilities. These are enhanced versions of the original programs but most development has been directed towards graphical and object oriented input. The analysis engine is much the same as 30 years ago. These programs permit some nonlinearity, but this is restricted to base isolation systems for dynamic analysis; nonlinearity in frame elements is restricted to static analysis.

The fully nonlinear structural analysis programs, such as RUAUMOKO and ANSR, remain largely unused outside academia. There are some very powerful general purpose nonlinear analysis programs available, such ABAQUS, NASTRAN, LUSAS, ANSYS, LS-DYNA, but these are high cost and difficult to use efficiently in design offices.

This is not intended as a criticism of the suppliers of the SAP2000 and ETABS programs. They respond to user demand. It seems that the profession is not demanding the level of software which it is now technically feasible to provide.

\section{PROCEDURES FOR STRUCTURAL ANALYSIS}

Analysis for earthquake loads differs from the analysis for most other load types in two important respects:

1. The loads change rapidly with time - dynamic.

2. The structure is loaded beyond the elastic limit nonlinear.

The four most common analysis methods, listed in Table 2, cover all permutations of these two features. A response spectrum analysis, common for new buildings, includes dynamic effects but not nonlinear elements. A pushover analysis, becoming common for existing buildings, includes nonlinear elements but not dynamic effects.
Although structural analysis is grouped within the category of finite element analysis, it is usually based on macromodelling rather than the micro-modelling of detailed finite element analysis. For example, frame elements such as beams and columns are usually modelled as a single element spanning a bay or story. Shear walls are often formed of a single plate element the width of the wall and a full story high.

Figure 2 shows an example of a structural model of the Beehive, a large and complex building. This model has 9716 degrees of freedom and 6200 elements, which is relatively small in terms of finite element analysis models but large in terms of structural analysis models. A model of this complexity takes 2-3 hours on a desktop computer for a nonlinear time history analysis of 2000 time steps.

As for all finite element analysis, the stiffness, mass and possibly damping matrices are formed and used to solve for displacements under a set of applied loads. This solution is theoretically based. However, the properties used to define the matrices, particularly the stiffness matrix, are based on rules developed from experimental data. This applies to linear elastic analysis, where adjustments are made to the elastic stiffness to allow for cracking, joint stiffness etc, and more so to nonlinear analysis where the stiffness of the element needs to be defined beyond the elastic limit. 


\begin{tabular}{llcc}
\multicolumn{1}{c}{ Type } & Usual Name & $\begin{array}{c}\text { Dynamic } \\
\text { Effects }\end{array}$ & $\begin{array}{c}\text { Material } \\
\text { Nonlineari } \\
\text { ty }\end{array}$ \\
\hline Linear Static & Equivalent Static & No & No \\
Linear Dynamic & Response Spectrum & Yes & No \\
Nonlinear Static & Pushover Analysis & No & Yes \\
Nonlinear Dynamic & Time History & Yes & Yes \\
\hline
\end{tabular}

Table 2 Hierarchy of Structural Analysis Methods

The stiffness for nonlinear analysis is based on a number of rules to cover factors such as the post-yield stiffness, the unloading stiffness, the reloading stiffness and degradation under repeated cycles. There are also interactions between force components, such as bi-axial moments and axial load, and perhaps also shear, in frame elements.

Attempts have been made to develop these rules analytically, or to have them implicit in the analysis, by using what are called fibre models. These models subdivide a plane section into a number of increments with a stress-strain function defined for each increment. This procedure adds enormously to the complexity of the model and the results still have a large amount of uncertainly due to statistical variations in properties such as concrete cracking stress and steel yield stress.

Rather than more detailed models, a more efficient approach is the use of macro models with detailed element hysteresis rules based on empirical evidence. There is a large amount of experimental data available, such as tests of beam-column assemblies and wall segments. However, the data have been processed to provide design rules rather than analysis rules. Design rules are based simply on the envelope skeleton curve. Details which are important to analysis, such as postyield stiffness, unloading stiffness etc are often not reported.

\section{NONLINEAR AND DYNAMIC EFFECTS}

The most common dynamic analysis used for seismic design is a response spectrum analysis, a statistical method. Results are not in equilibrium, not only due to the loss of signs but also because quantities are not consistent - for example, in a 10 story flexural building the inertia force distribution, the distribution providing maximum shear forces and the distribution providing maximum moments are all different, as shown in Figure 3.

The statistical combination of results causes problems in design quantities such as drifts, which are not necessarily the difference in displacements between adjacent stories, and elements for which force combinations need to be combined, such as columns where strength is a combination of axial load and moments.

When yielding occurs in a structure the force distributions adapt to the constraint formed by the yielding. The type of force distribution depends on the type of yield:

1. For a limitation in maximum base moment, such as for a cantilever wall with a hinge at the base, the distribution will adapt so as to produce the maximum shear force consistent with this moment constraint.

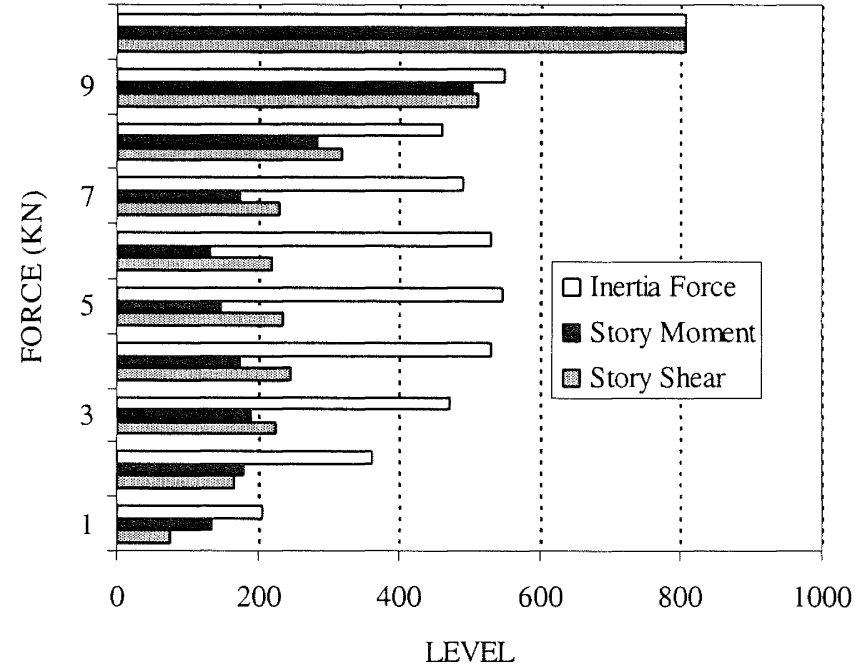

Figure 3. Response Spectrum Forces 


\subsection{Frame Structures}

In frame structures the strength of the elements provides a limit in the base overturning moment. This limit is the sum of the column base moment yield strengths plus the limit on column overturning loads imposed by beam yield strength

When the base moment is limited, the force distribution adapts so as to maximise the shear force within this limit. The inertia forces at upper levels decrease and those at lower levels increase, producing the change in shear force shown in Figure 4. This results in a base shear force twice as high as that at the time of maximum base moment.

Figure 5 shows the column bending moment patterns at the time of maximum moment and maximum shear. The high shear at the lower levels occurs within the constraint of a maximum beam moment strength by a change in location of the points of contraflexure in the columns immediately above the first story.

The changes in column moments shown in Figure 5 were identified about 30 years ago and empirical factors are adopted to account for this in design, such as the $\omega$ factors in the New Zealand code.

\section{Maximum Base Moment}

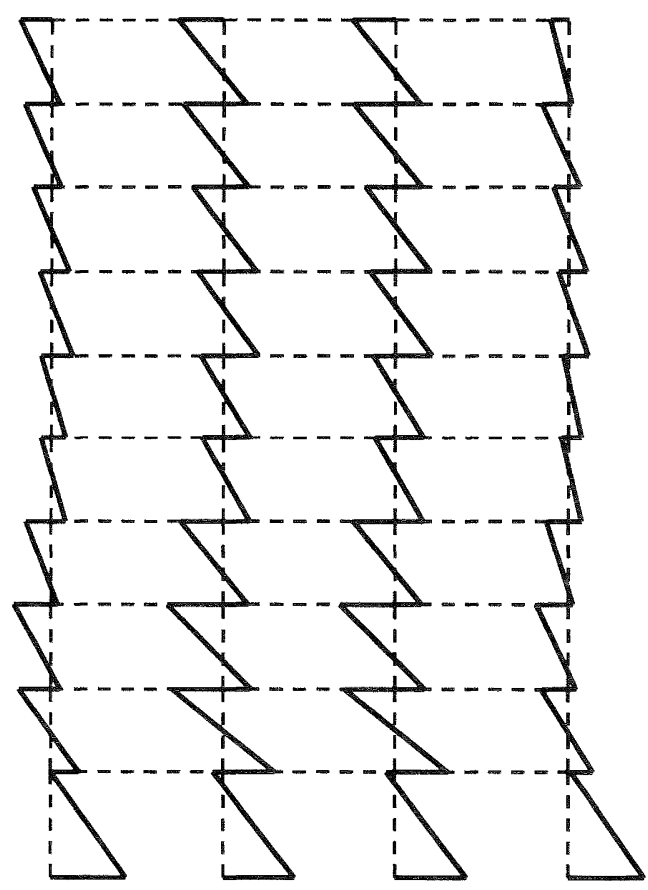

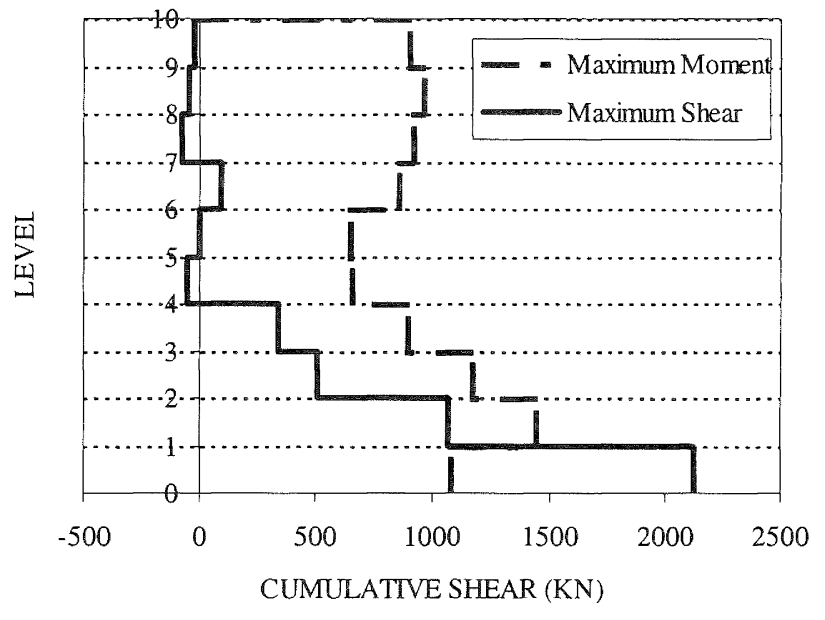

Figure 4. Story Shear Distribution
Maximum Base Shear

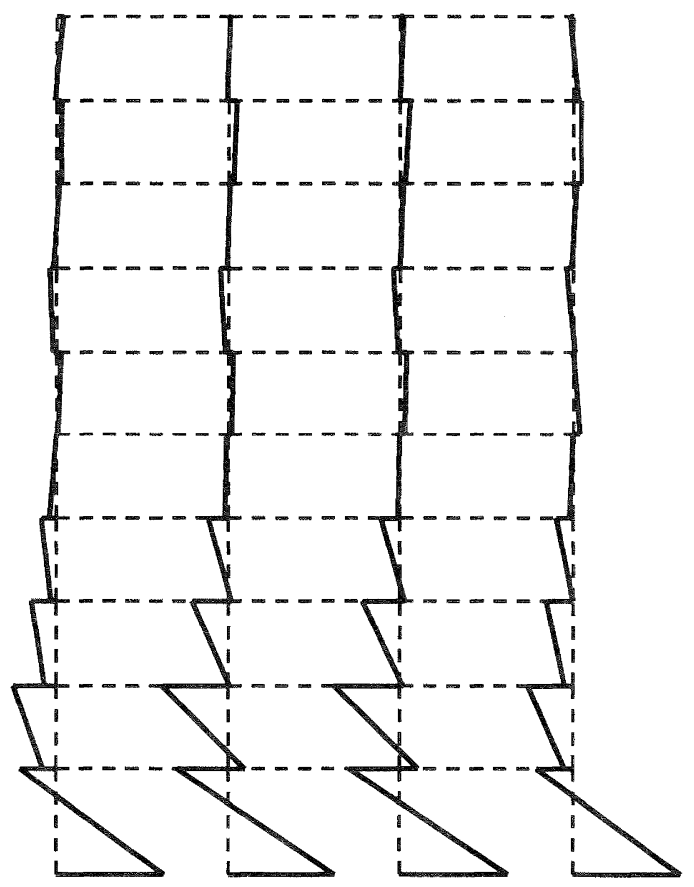

Figure 5. Bending Moment Distributions 


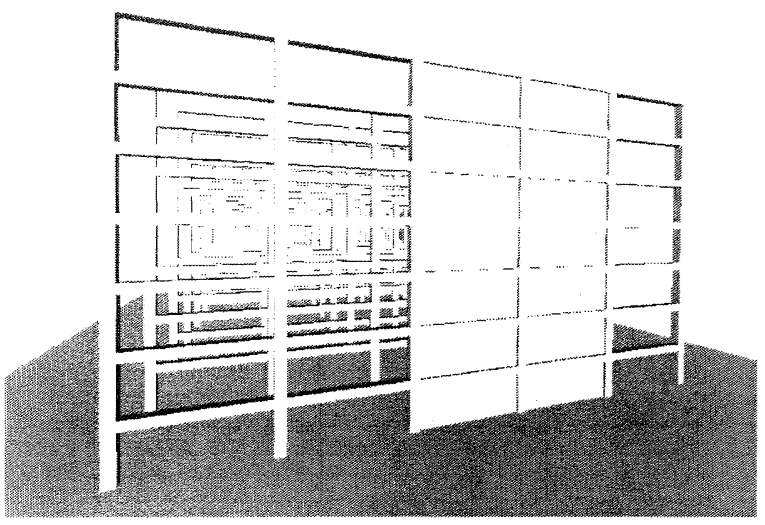

Figure 6. Rocking Shear Walls

\subsection{Rocking Structures}

Structures which rock are an extreme case of the cantilever shear wall which yields at the base. As an example of the

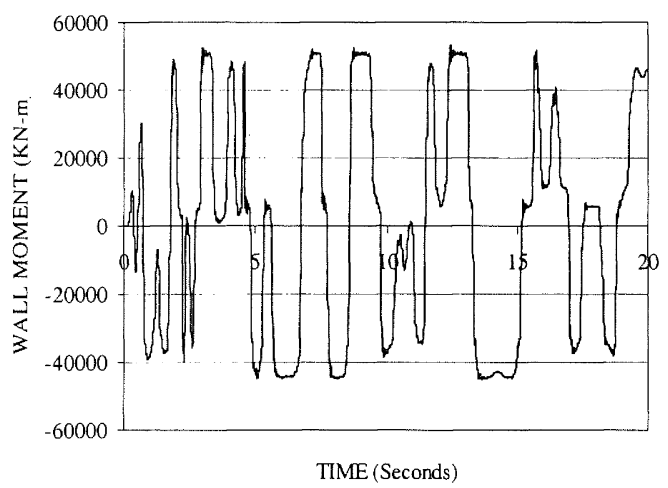

Figure 7. Time History of Base Moment

shear distributions occurring in a rocking structure, consider the 7 story building shown in Figure 6.

The end walls in this building are permitted to rock under seismic loads. The maximum moment at the base of the wall is limited by the wall geometry and the gravity loads on the wall.

A time history analysis exhibits this base moment limitation, as shown in the time history of base moment in Figure 7. For design, it was expected that the wall shear force would be similar to that obtained from an elastic analysis scaled to the same base moment.

In fact, the wall shear force was over two times as high as expected. The elastic inertia force distribution is an inverted triangle shape with a peak at roof level. As shown in Figure 8 , this force distribution inverts at the time of maximum wall shear force, with maximum inertia forces at the lower levels. This allows the wall shear force to increase within the constraint of a maximum base moment. As for frames, this effect is included in shear design of walls by magnification factors, $\omega$.

\subsection{Isolated Structures}

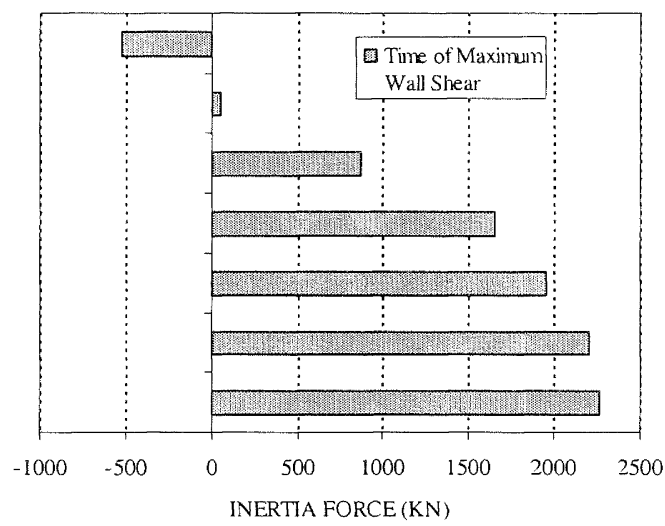

Figure 8. Inertia Force Distribution

Base isolated structures are another extreme case of a base strength constraint, in this case a constraint in base shear force rather than base moment as for a rocking wall. Table 3 summarises the base actions for an eight story frame with various types of base isolation system. These actions are at the time steps which produced (a) the maximum base shear force and (b) the maximum base overturning action respectively.

The first columns in Table 3 list the base moment, $\mathrm{M}$, and shear, $\mathrm{V}$, at the time step when the maximum base shear occurred. The ratio $\mathrm{M} / \mathrm{VH}$ indicates the ratio of the height of the centroid of the applied forces to the building height, $\mathrm{H}$. A value of 0.67 indicates a linear increase with height, the triangular distribution used in codes for static loads. A value of 0.50 indicates a uniform distribution of loads, that is, no amplification with height, an assumption often made for isolated structures.

The results at the time of maximum base shear show that the structure with no isolation system is close to the triangular assumption, with a centroid at $0.61 \mathrm{H}$. The isolated options tend to be closer to a uniform distribution of $0.50 \mathrm{H}$, except for the high damping rubber which is close to a triangular distribution.

However, this changes dramatically for the isolated configurations when the distribution at the time of maximum base moment is considered. The non-isolated building centroid at $0.72 \mathrm{H}$ slightly exceeds the $0.67 \mathrm{H}$ value for a triangular distribution, a pattern which is recognised by codes applying part of the load at roof level. Of the isolation systems, the elastic system centroid stays the same but for all the nonlinear systems the centroid increases so as to have an effective height of application greater than $\mathrm{H}$. This implies an inertia load pattern with forces of reversing sign, as shown in Figure 9 (c) and (d) for the lead rubber and friction pendulum systems. 
Table 3. Base Isolation Systems

\begin{tabular}{|l|c|c|c|c|c|c|}
\hline \multirow{2}{*}{$\begin{array}{l}\text { Type } \\
\text { Isolation System }\end{array}$} & \multicolumn{3}{|c|}{$\begin{array}{c}\text { At time of maximum } \\
\text { base shear }\end{array}$} & \multicolumn{3}{c|}{$\begin{array}{c}\text { At time of maximum } \\
\text { base moment }\end{array}$} \\
\cline { 2 - 8 } & $\begin{array}{c}\text { Moment } \\
\mathbf{M} \\
(\mathbf{K N}-\mathbf{m})\end{array}$ & $\begin{array}{c}\text { Shear } \\
\mathbf{V} \\
(\mathbf{K N})\end{array}$ & $\frac{\mathbf{M}}{\mathbf{V H}}$ & $\begin{array}{c}\text { Moment } \\
\mathbf{M} \\
(\mathbf{K N}-\mathbf{m})\end{array}$ & $\begin{array}{c}\text { Shear } \\
\mathbf{V} \\
(\mathbf{K N})\end{array}$ & $\frac{\mathbf{M}}{\mathbf{V H}}$ \\
\hline None & 81,124 & 4589 & 0.61 & 85,858 & 4069 & 0.72 \\
\hline Elastic & 21,553 & 1338 & 0.55 & 21,626 & 1336 & 0.55 \\
\hline Lead Rubber & 11,983 & 828 & 0.50 & 18,551 & 538 & 1.18 \\
\hline High Damping Rubber & 20,476 & 1031 & 0.68 & 27,090 & 608 & 1.53 \\
\hline Friction Pendulum & 12,773 & 971 & 0.45 & 16,924 & 456 & 1.27 \\
\hline
\end{tabular}

(a) NON-ISOLATED STRUCTURE

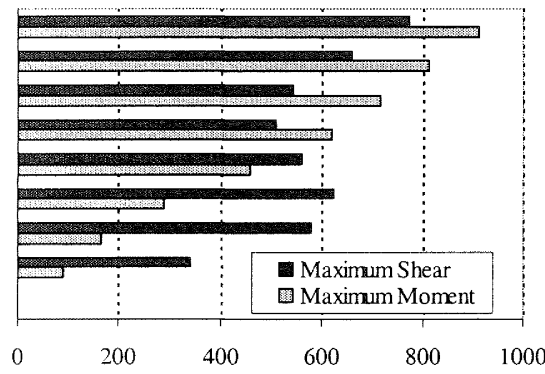

(c) LEAD RUBBER SYSTEM

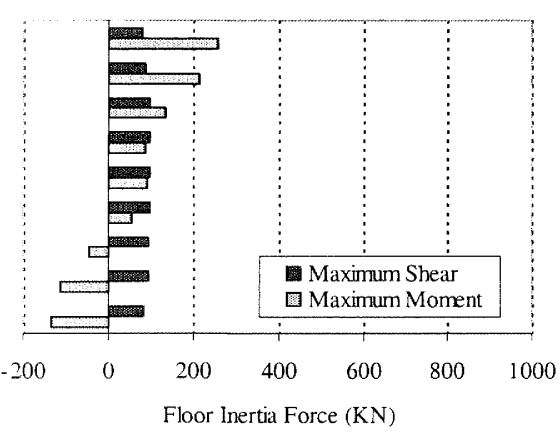

(b) ELASTIC ISOLATION SYSTEM

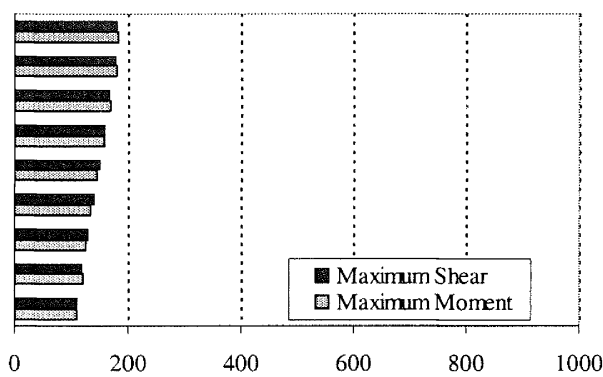

(d) FRICTION PENDULUM SYSTEM

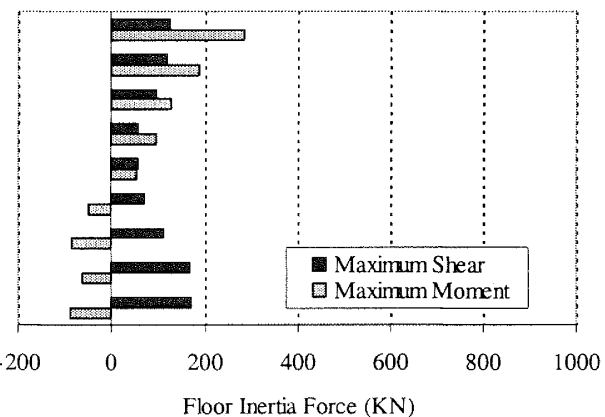

Floor Inertia Force $(\mathrm{KN})$

Figure 9. Isolation System Force Distributions

A common method for the analysis of base isolated structures is the equivalent stiffness method, where the secant stiffness at the estimated maximum displacement is used to define an equivalent elastic system. This linearization permits the response spectrum method of analysis to be used. When this assumption is made, the shear force distribution of all systems will be equivalent to that shown for the elastic isolation system in Figure 9 (b), rather than the more complex distributions in Figures 9 (c) and (d). As shown by the maximum moments in Table 3 , this will lead to a severe underestimation of overturning.

\subsection{P-Delta Effects}

P- $\Delta$ (second order or geometric stiffness) effects are difficult to quantify using linear elastic techniques, as shown by the procedure in NZS4203, where second order effects are approximated as a set of static loads. If the response spectrum analysis method is used for primary loads then the load types are incompatible for combination.

From observation of the results of non-linear analyses, comparing the response with and without geometric stiffness effects, P- $\Delta$ effects are most significant when two conditions are met:

1. A complete yielding mechanism forms and

2. There is little, or no, strain hardening after the mechanism forms. 
Figure 10 illustrates how important the strain hardening is for second order effects. This figure plots the maximum story drift ratios for a 10 story building with and without P- $\Delta$ effects for varying strain hardening.

Ignoring P- $\Delta$ effects, the response is insensitive to strain hardening with a drift of $1.31 \%$ at $0 \%$ reducing to $1.03 \%$ at $10 \%$ strain hardening.

When P- $\Delta$ effects are included the response is very sensitive to the strain hardening ratio and, in fact, when there is zero strain hardening the structure does not survive the earthquake.

This sensitivity to the yielded stiffness arises because P- $\Delta$ loads apply a negative stiffness equal to $-\mathrm{P} / \mathrm{H}$.

If the post-yield stiffness exceeds this value then the lateral system will be stable, otherwise it will be in an unstable equilibrium and will collapse if the earthquake is of sufficient amplitude. This is illustrated by the time history of response in Figure 11. A strain hardening of $10 \%$ returns the structure to the zero displacement baseline, whereas with $2 \%$ strain hardening a permanent set of $500 \mathrm{~mm}$ occurs and at $0 \%$ strain hardening collapse occurs.

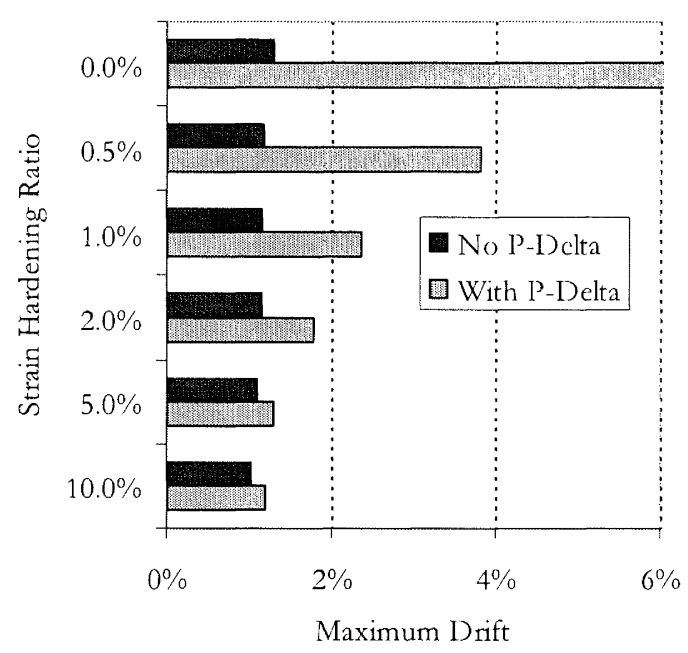

Figure 10. P-AEffects

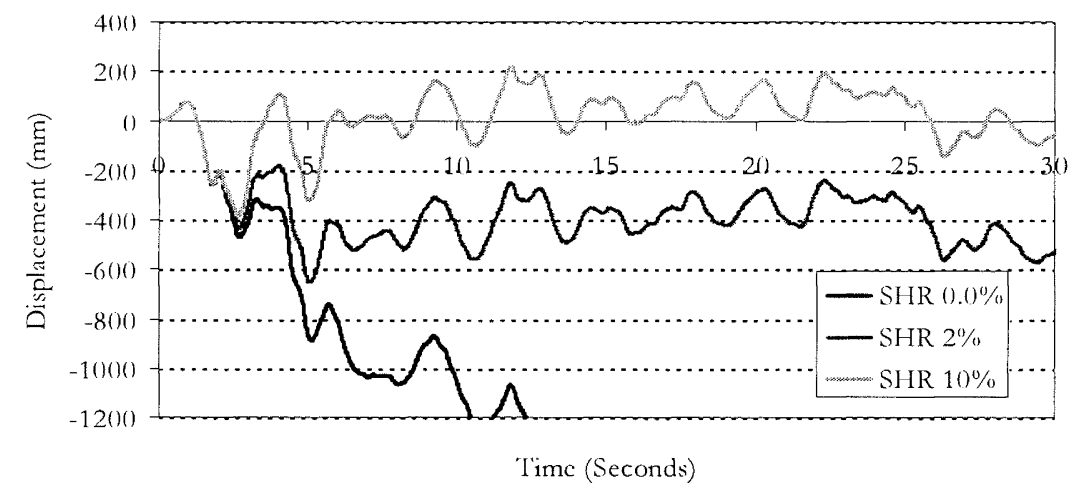

Figure 11. Effect of P-A on Time History

Our design strategy for earthquake loads is based on ensuring that a desirable mechanism forms and so we tend to design for condition 1, a complete yielding mechanism. Research on structural components almost never reports the postyielding stiffness of elements, whereas for P- $\Delta$ this is a critical parameter. This suggests that perhaps we should be detailing our yielding components so that they retain a positive strain hardening stiffness greater than the negative $\mathrm{P}$ delta stiffness.

\subsection{Irregular and Unusual Structures}

The seismic response of irregular structures is highly influenced by both dynamic and nonlinear effects. Structures may be irregular because of the geometry, because of the use of structural systems of different strength and/or stiffness properties or by the use of seismic mitigation measures such as base isolation. For irregular buildings, a nonlinear time history analysis is often the only practical method of assessing seismic performance

\subsubsection{Vertical Irregularity.}

An example of vertical irregularity is a flexible structure constructed above a stiff structure, such as shown in Figure 12, which is a structural model of the Downtown Parking Building in Auckland. Depending on the period ratio, the flexible structure may amplify response of the stiffer restructure or, conversely, may act as a tuned mass damper and reduce response. This can be accurately assessed only with a time history analysis because yielding changes the period of the supporting structure, and so modifies the input to the flexible structure above. 


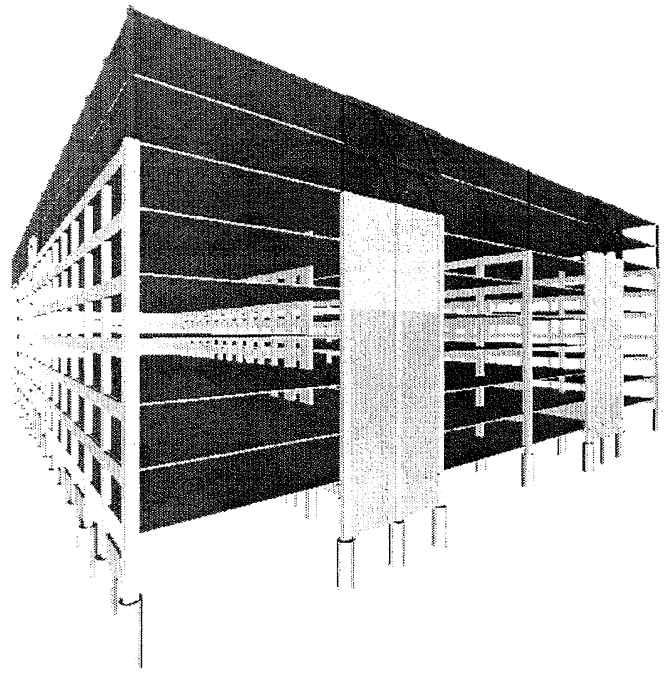

Figure 12. Adding Floors to Existing Building

\subsubsection{Existing Buildings}

Seismic strengthening of existing buildings, such as the Christchurch Cathedral shown in Figure 13, often requires the addition of materials and components with properties very different from the original materials.

It is important that the interaction between the new and existing materials be assessed and this can only be achieved with a nonlinear analysis which models the change in stiffness in the materials under seismic loads. Adding a flexural structural system, such as a steel frame, may not be effective as the deformations under seismic loads may be such as to fail existing components.

Conversely, adding stiff components such as reinforced concrete walls will increase accelerations within the structure and may cause failure of existing components.

Many of these effects will not be apparent if either dynamic effects or nonlinearity are ignored and so a comprehensive strengthening evaluation requires an extensive series of time history analyses.

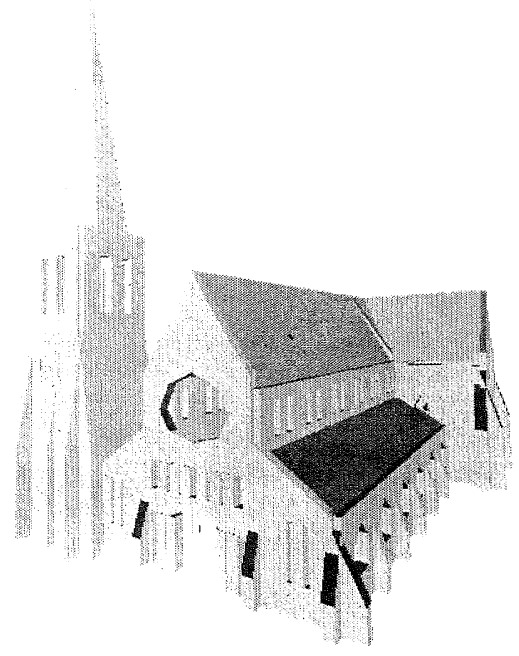

Figure 14. Adding Strengthening

\subsubsection{Pounding Buildings}

Many older buildings in the Central Business Districts were constructed early last century with little or no separation between neighbouring buildings. In low seismic zones the buildings may have sufficient strength on an individual basis. However, pounding by adjacent buildings may impose additional loads.

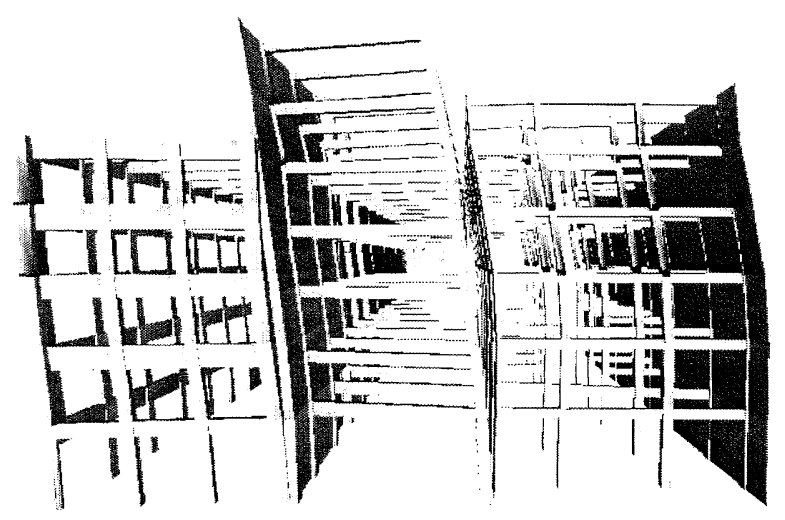

Figure 13. Pounding Buildings

Figure 14 shows an example of a project in Queen Street, Auckland, where a combined model of three buildings was used to evaluate the effects of pounding between adjacent buildings. This effect becomes especially important where the floors of adjacent buildings are at different elevations. This may cause large plastic rotations at mid-height of walls or columns.

Pounding can be evaluated analytically, although the procedure is very computationally intensive. The impact causes high frequency acceleration pulses and a very small time step is required to capture these, typically 0.001 seconds or less.

\subsubsection{Rocking and Uplifting Buildings}

Many existing buildings, and some new buildings, have insufficient weight to resist overturning loads without uplift of structural elements.

Uplift can be prevented by the use of foundation elements such as tension piles. For new buildings, this is the usual solution even though it is known from actual earthquakes that limited uplift does not cause severe damage. The problem with permitting uplift is that the deformations, and the associated redistribution of forces, cannot be quantified using linear elastic analysis.

A time history analysis can quantify these effects, as for example the Canterbury University Student Union building shown in Figure 15. In this building the walls are founded on strip footings without tension piles and under ultimate earthquake loads uplift occurs at wall ends. This has a number of effects which influence response:

1. The wall shear distribution adapts, as discussed earlier, and the shear stress in the wall may be twice as high as expected from an elastic analysis. 


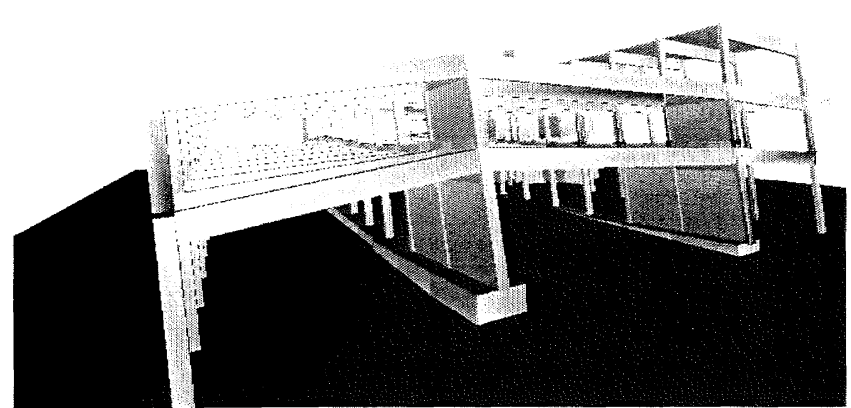

Figure 15. Uplifting Foundation

2. The uplifting element will induce shear forces in connecting elements, in this case the beams. The shear distributions in these elements will also be significantly different from that expected from a linear analysis.

3. The soil under the wall will be subjected to amplified forces due to wall impacts.

\subsubsection{Base Isolation and Damping}

Base isolation and added energy dissipation devices function by changing the dynamic properties of the system. In addition, almost all practical isolation systems, and most damping systems, have nonlinear properties. Isolators are usually nonlinear with displacement, dampers are nonlinear with displacement or velocity.

An example of a base isolated building which also has added dampers is Union House in Auckland, shown in Figure 16.

Some codes, such as the U.S Uniform Building Code, permit equivalent elastic analysis for buildings with isolation and/or energy dissipation. As discussed earlier, this approach is only valid for systems with linear properties, which are very unusual. For the more common case of nonlinear isolators or dampers a response spectrum analysis cannot capture the change in inertia force distribution which occurs subsequent to yielding. This can lead to a severe underestimation of overturning moment effects. In general, the more nonlinear the system the more extreme the variations in the inertia force distributions (Kelly, 2001a).

\section{IMPEDIMENTS TO USE OF NONLINEAR ANALYSIS}

The examples above have shown that many structural configurations exhibit a complex dynamic response which can only be captured by nonlinear dynamic analysis. For the design of even regular frame and shear wall structures, codes approximate the change in inertia force distributions by the use of $\omega$ factors. As nonlinear analyses can incorporate these effects explicitly, it follows that these would lead to a more accurate assessment of the response of structures to earthquake loads.

The fact that nonlinear analysis remains rare suggests that there are impediments to its use and this is in fact the case. Impediments include uncertainties relating to structural properties after yielding and the selection of appropriate time histories. Although these uncertainties exist in all methods of analysis, it is only in dynamic nonlinear procedures that they are explicit. Linear elastic models ignore all yielding effects and static and pushover analyses ignore variations in dynamic loads with time so these uncertainties do not need by addressed.

\subsection{Unresolved Modelling Issues}

There are a number of aspects of nonlinear modelling which affect results and which are currently unresolved. Major items which have been identified by the New Zealand Society for Earthquake Engineering study group (NZSEE, 2002) include:

- Inappropriate hysteresis rules

- Definition of damping.

- Onset of shear failure - interaction between flexure, shear, axial load.

- Influence of axial force on column stiffness.

- Degrading strength in general, beam-column joints in particular.

These items are amenable to the development of rule-based analysis procedures, provided sufficient empirical data exist to define them for a full range of response. In many cases, the experimental evidence exists but the rules have not been derived from this.

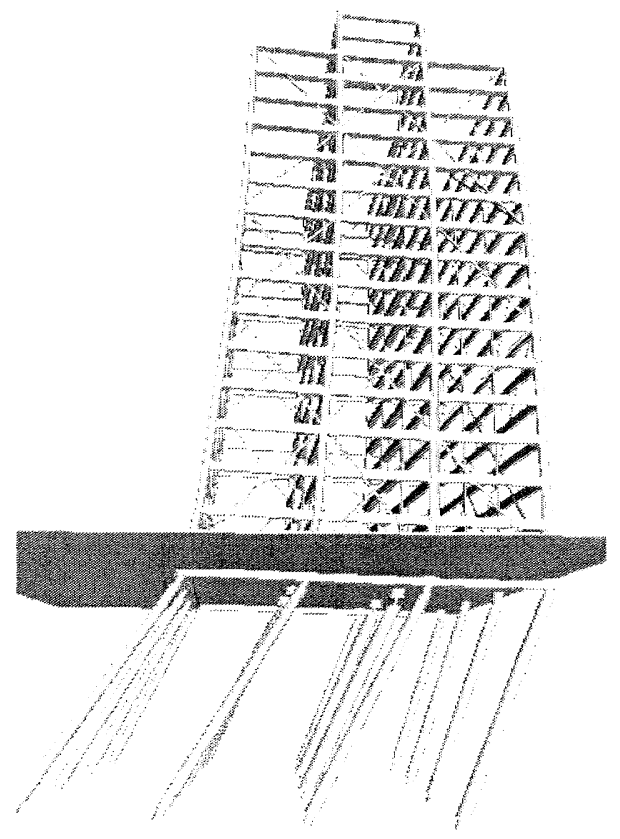

Figure 16. Base Isolated Buildings

\subsection{Selection of Time Histories}

The selection of appropriate time histories is a major unresolved issue. A selection of time histories which produce a similar response spectrum will produce a large variation in nonlinear response. Figure 17 shows the variation in base shear for an elastic and an inelastic structure responding to a series of time histories. Each record was frequency scaled to the same response spectrum so that the elastic response was within $\pm 10 \%$ of the target spectrum. When these records were used to evaluate nonlinear response 
the variation was much greater, $\pm 25 \%$. This suggests that the response spectrum does not contain all information determining structural response

(b) NONLINEAR RESPONSE

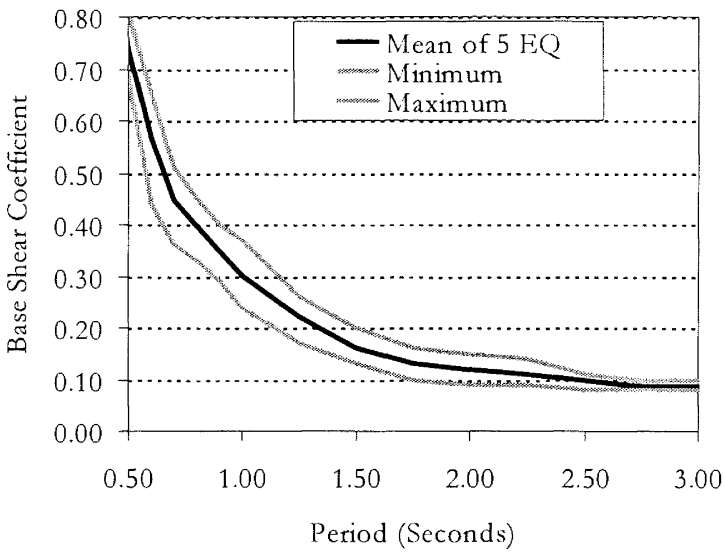

Period (Seconds)

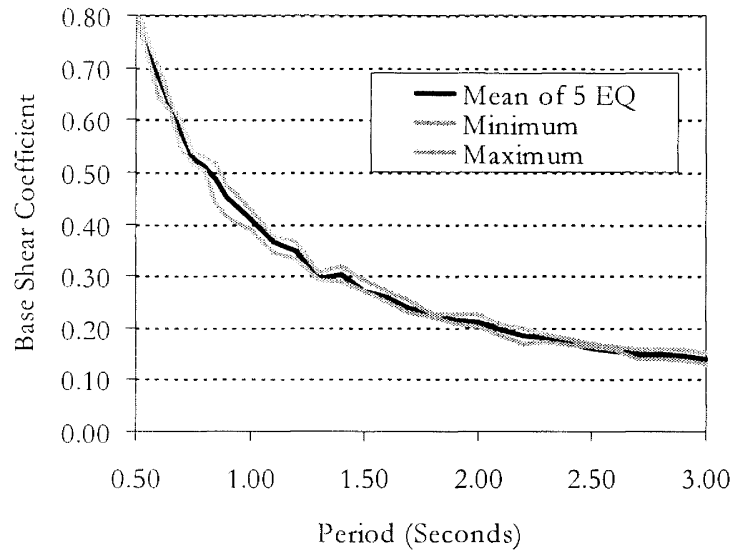

Figure 17. Effect of Nonlinearity on Response Variation

It has long been known that the response of yielding structures is dependent on the maximum velocity and incremental velocity in the acceleration record (Bertero, 1976). This information is not contained in an acceleration response spectrum and so records providing a similar spectral shape can produce quite a different response for yielding structures.

For a level of nonlinear analysis to be equivalent to a response spectrum analysis, a single time history which had been frequency scaled to match the spectrum would be sufficient. However, the expectations of time history analysis are higher and so multiple records are used.

The effect of using multiple time histories is that input is closer to the maximum response, rather than the mean response represented by a response spectrum. Figure 18 plots the response spectra from 10 earthquakes specified by ATC-40 (ATC, 1996) for sites distant from the fault, each scaled to an $0.4 \mathrm{~g}$ maximum ground acceleration. The mean spectrum has a spectral shape generally similar to that used in design codes. However, the maximum values are typically about twice as high. Effectively, this requires that a time history analysis be performed for a much higher level of input than procedures based on static loads or response spectra. The use of concurrent components also adds to the demand on the structure when nonlinear analysis is used.

\subsection{Lack of Software}

The original computer programs for nonlinear analysis were complex. Much of this complexity was a function of hardware and compiler limitations of the time, in particular, the small amount of available memory and the inability of the compilers to allocate this memory at run time. These restrictions no longer apply but it takes a large effort to convert the old code to more modern syntax.

The market for finite element analysis packages specific to the needs of structural engineers is relatively small. The small market deters private companies from investing in this effort.

\subsection{Complex Input / Output}

Time history analysis has the reputation of difficult input preparation. Modern computers can perform nonlinear

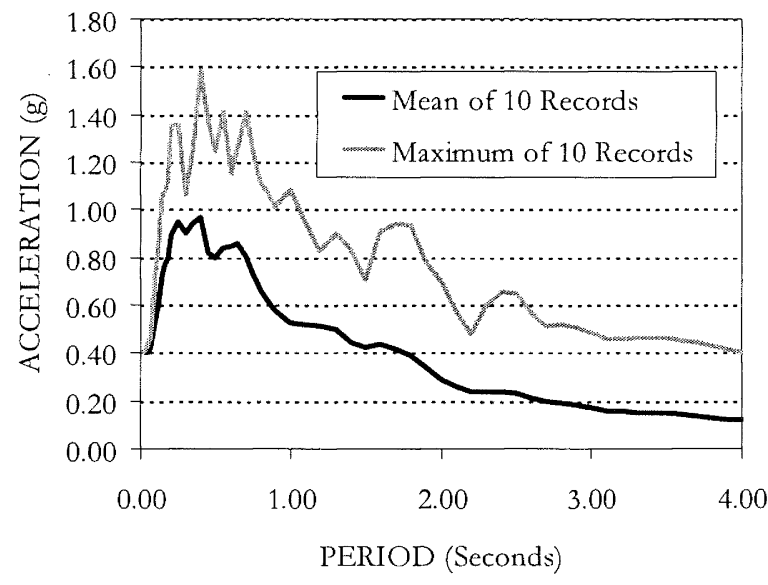

Figure 18. 5\% Damped Spectra

analysis on a model of the same refinement used for linear elastic analysis and so the data preparation can be the same as for this more familiar procedure. Additional data is required, describing the strength and hysteretic properties but this data is becoming more prescriptive with developments in performance based design (FEMA, 2000).

The procedure in our company is to use Excel $^{\odot}$ spreadsheets for input and output (Kelly, 200lb) to the ANSR-II analysis 
program (Mondkar, 1979). The programming language built into spreadsheets allows the data to be formatted and the model assembled from the same user input for different analysis programs. Similarly, programs can be used to read output files from multiple analyses and import results into spreadsheets for further processing.

\section{CURRENT DEVELOPMENTS}

Current analysis developments in structural engineering analysis are focused on forms of secant stiffness analysis, where the actual nonlinear behaviour is replaced by an equivalent elastic system. These are termed displacement based analysis and pushover analysis.

The main limitation of these forms of analysis, that they do not incorporate the change in inertia force distribution as yielding occurs, is being addressed by the use of so-called adaptive load models. In the limit, an adaptive load model will converge to a step-by-step time history analysis. However, this is a very indirect procedure to approach this end result.

As adaptive static loads are moving toward the methodology of time history analysis, a more efficient development would seem to be to address these efforts toward removing the impediments which have been identified. A nonlinear time history analysis could then form the basis for a comprehensive performance based procedure.

\section{CONCLUSIONS}

Almost all structural design and evaluation is still based on the procedures used 30 years ago, either an equivalent static analysis or a response spectrum analysis. These procedures cannot assess the effect of nonlinear response. Recent developments in the profession have been toward nonlinear static procedures, such as displacement based design or pushover analysis. Although these procedures do include the effect of nonlinearity, they do not include dynamic effects.

For a wide range of structural types, nonlinear time history analyses have shown that the response is very much influenced by both dynamic and nonlinear effects. These include rocking structures, structures with vertical irregularity, existing buildings and buildings which use mitigation measures such as base isolators or dampers. Even for regular structural types such as ductile frames and cantilever walls the force distributions determined from nonlinear dynamic analyses differ widely from that obtained from other forms of analysis.

Computer programs capable of performing three dimensional nonlinear time history analysis were developed almost 30 years ago but were not widely used because of hardware limitations. Although this limitation no longer exists, this type of analysis is still not widely used because the effort has not been made to adapt these programs to suit modern hardware.

The major existing impediments to nonlinear analysis relate to modelled properties, time history selection and complexity of the analysis. None of these represent insurmountable problems. Sufficient research data exists to define properties; computer hardware permits analysis for multiple time histories; and data preparation and output processing can be simplified using spreadsheet tools used so widely in other aspects of structural design.

As the profession moves toward performance based design and evaluation, we should be using the best possible tools to assess the performance as accurately as possible. Nonlinear time history analysis is the most comprehensive method available to use and we should act to remove impediments to its use.

\section{REFERENCES}

ATC (1996). Seismic Evaluation and Retrofit of Concrete Buildings, ATC 40, Applied Technology Council, California.

Bertero, V.V. (1976). "Identification of Research Needs for Improving the Aseismic Design of Building Structures", Bulletin of the New Zealand National Society for Earthquake Engineering, Vol. 9, No. 1

Courant, R. (1943). "Variational Methods for the Solution of Problems of Equilibrium and Vibrations", Bulletin of the American Mathematical Society Vol 49, 1-23.

FEMA, (2000). Prestandard and Commentary for the Seismic Rehabilitation of Buildings, FEMA 356, Federal Emergency Management Agency, Washington D.C.

Habibullah, A. (2001). ETABS Users Manual and SAP2000 Users Manual, Computers and Structures Inc, Berkeley, CA.

Kelly, T.E. (2001a). "Base Isolation of Structures - Design Guidelines", Holmes Consulting Group, available from www.holmesgroup.com

Kelly, T.E. (2001b). "Performance Based Evaluation of Buildings - Nonlinear Pushover and Time History Analysis - Reference Manual", Holmes Consulting Group, available from www.holmesgroup.com

Mondkar, D.P. and Powell, G.H., (1979). "ANSR II Analysis of Non-linear Structural Response User's Manual", EERC 79/17, University of California, Berkeley, July.

NZSEE Study Group, (2002). "Assessment and Improvement of the Structural Performance of Buildings in Earthquake". New Zealand Society for Earthquake Engineering, Draft for Comment.

Rayleigh, Lord, (1877). Theory of Sound (two volumes). New York

Turner, M. J., Clough, R.W., Martin, H.C. \& Topp L.J. (1956). "Stiffness and Deflection Analysis of Complex Structure", Journal of Aeronautical Science, Vol. 23, 805 824 